\title{
A Distinct Parallel Attachment System for the Rehabilitation of Kennedy's Class 2 Partially Edentulous Arch - A Case Report
}

\author{
Meekha Peter ${ }^{1}$, Mahantesh Bembalagi², Hema Kanathila ${ }^{3}$ \\ 1, 2, 3 Department of Prosthodontics, KAHER'S KLE VK Institute of Dental Sciences, Belgaum, Karnataka, India.
}

\section{INTRODUCTION}

Among the numerous techniques of oral rehabilitation, precision attachments are considered as a good treatment option in removable (RPD) as well as fixed partial dentures (FPD). Precision attachments enhance patient's self-confidence and selfimage as they help in facilitating aesthetic, functional and retentive replacement of teeth that are missing in the oral cavity. They can improve the aesthetics by eliminating the clasp assembly in cast partial dentures (CPD). This particular case report explains the treatment sequence and approach for the utilisation of attachments in a Kennedy Class 2 situation.

A successful removable partial denture includes a precise diagnosis with meticulous treatment planning. However, re-establishment of partially edentulous arch is particularly challenging in distal extension situations classified as Kennedy's class 1 or 2 conditions. ${ }^{1}$ In such clinical cases, where a fixed prosthesis cannot be fabricated, a prosthodontist often suggests an implant retained prosthesis that is not routinely possible because of the insufficient available bone width and height. ${ }^{2}$ Thus to ensure functional and aesthetic substitution of lost teeth, an attachment secured RPD can be considered as a good treatment option in such cases.

Attachments are constructed in a ready to place form (pre-fabricated) known as precision attachments. Another one is semi precision attachment where the segments have to be constructed by dentists or dental technicians because it requires casting for incorporating into fixed unit of restoration. ${ }^{3}$ Hence precision attachments are considered as possible alternatives when patients demand for a fixed restoration in distal extension cases.

Various extra coronal attachments are available and used in distal extension cases. Preci-Sagix is considered as an ideal extra coronal attachment for removable partial dentures and also in over denture cases. It is accessible in two sizes, $1.7 \mathrm{~mm}$ mini or $2.2 \mathrm{~mm}$ standard and is selected according to the permitted space. The male component is available in three varieties, a plastic castable pattern (any hard alloy), cast to no prax (only non-precious alloy) and a threaded male and base ring ( $2.2 \mathrm{~mm}$ size only). ${ }^{4}$ These attachments produce vertical, horizontal and rotational movements during its function which supports the prosthesis by transferring harmful forces from the abutments to the supporting structures by its passive movement, which helps in the rehabilitation of distal extension cases. ${ }^{5}$

This case report explains restoration of partially edentulous arch by incorporating a Preci Sagix attachment in mandibular cast partial denture retained by a six-unit FPD and a maxillary conventional cast partial denture.
Corresponding Author:

Dr. Meekha Peter,

KAHER'S KLE V K Institute of

Dental Sciences, Belgaum,

Karnataka, India.

E-mail:meekhapeter@gmail.com

DOI: $10.14260 / \mathrm{jemds} / 2021 / 268$

How to Cite This Article:

Peter M, Bembalagi M, Kanathila H. A distinct parallel attachment system for the rehabilitation of Kennedy's class 2 partially edentulous arch - a case report. J Evolution Med Dent Sci 2021; 10(17):1265-1268, DOI: 10.14260/jemds/2021/268

Submission 15-12-2020,

Peer Review 25-02-2021,

Acceptance 01-03-2021,

Published 26-04-2021.

Copyright (C) 2021 Meekha Peter et al. This is an open access article distributed under Creative Commons Attribution License [Attribution 4.0 International (CC BY 4.0)] 


\section{PRESENTATION OF CASE}

A 56-year-old female patient reported to the Department of Prosthodontics (KAHER'S KLE VK Institute of Dental Sciences, Belgaum, Karnataka) with a chief complaint of missing teeth in right and left lower posterior region of the jaw. Patient complained of difficulty in eating food properly due to compromised chewing efficiency, thus patient was demanding a fixed prosthesis. Patient's medical history was evaluated and was found to be irrelevant.

On examination, patient presented with a collapsed bite (Figure 1) and the missing teeth were 13, 15, 16, 23, 24, 26, 34, $35,36,37,44,45$, 46 (Figure 2 and 3). Remaining existing teeth in the patient's oral cavity were periodontally stable. Hence, to replace the lost teeth a semi-fixed prosthesis was considered which included splinted lower anterior crowns combined with an extra coronal attachment and a cast partial framework.
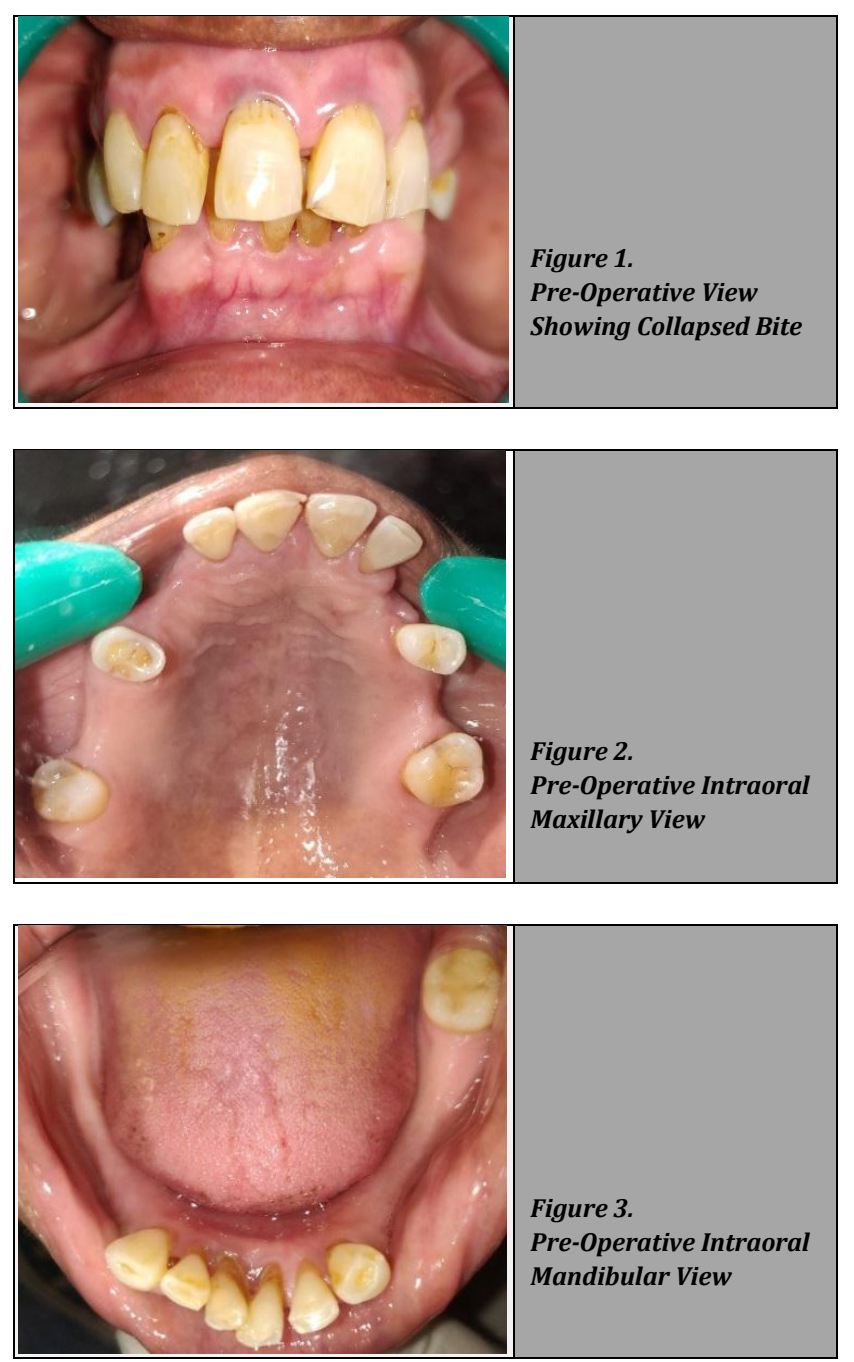

\section{DISCUSSION OF MANAGEMENT}

\section{Treatment Procedure}

Proposed treatment plan for the patient was a combined prosthesis with an extra coronal precision attachment for mandibular unilateral distal extension arch and cast partial denture for maxillary arch.

\section{Clinical Procedures}

Treatment was commenced by making diagnostic impressions of maxillo-mandibular arches with alginate (Tropicalgin, Zhermack, Italy). Following which a tentative jaw relation was recorded and transferred to the semi adjustable articulator (Hanau Wide-Vue) using the face bow as an adjunct. Subsequently diagnostic wax up was done wherein the vertical dimension of occlusion was increased by $2 \mathrm{~mm}$ in the articulator in order to regain patient's lost vertical dimension and a provisional removable prosthesis was provided to the patient to get accustomed to the new vertical dimension. Precisagix attachment system was decided depending upon the available space. Tooth preparation was performed with lower anteriors after intentional root canal treatment, i.e., 31, 32, 33, $41,42,43$ to receive porcelain-fused-to-metal crowns and a rest seat was prepared in 47 mesially. Final impressions were made after adequate gingival retraction was achieved. Provisional prosthesis (Temp-Bond, Kerr Corporation, Romulus) was fabricated in accordance with the diagnostic wax up and luted with temporary cement.

\section{Laboratory Procedures}

The final impressions were poured in die stone and wax patterns were made to full contour. Thereafter a box was created in the wax up to house matrices of extra coronal attachment to axial surfaces of the abutment using a surveyor, which ensures that bulk of matrices does not interfere with aesthetics of restoring denture tooth (i.e., $43 \& 33$ ) (Figure 4).
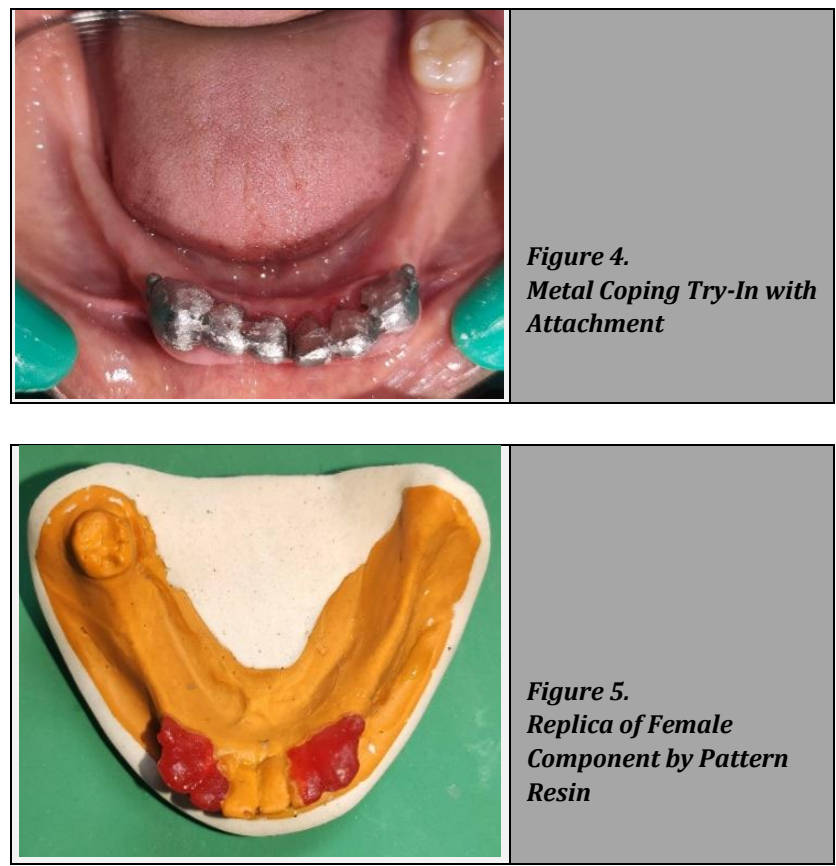

\section{Metal Coping Try In}

The prepared wax pattern was casted using conventional casting procedures. Try in of splinted metal copings was done to evaluate the fit, followed by the fabrication of final metal ceramic restoration. Extra precautions were taken during sandblasting and finishing procedures of casted prosthesis to eliminate abrasiveness of attachment. (Figure 5) 


\section{Checking the Fit of PFM Crowns and Pick Up Impression}

After metal coping try in, ceramic build up (VITA Zahnfabrik, Germany) and firing was performed on metal framework and checked in patient's mouth. These metal ceramic crowns were provisionally cemented with matrix attached to casting. A pickup impression with addition silicone was taken to obtain a cast for fabrication of metal framework.

\section{Housing in Framework}

Housing of the female component can be attained with pattern resin and a lingual bar cast partial framework was designed on a refractory cast and fabricated.

The framework was then tried in the patient with female component (yellow) inserted into the housing of cast partial framework against the position of patrix. Finishing of the female housing was done carefully to ensure the snap fit. (Figure 6 \& 7)

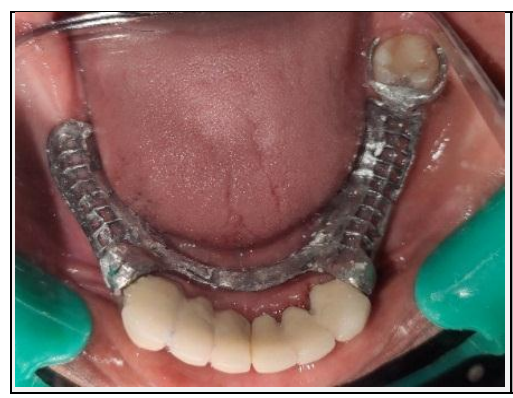

Figure 6.

PFM Crowns and Housing of CPD Framework against Attachment
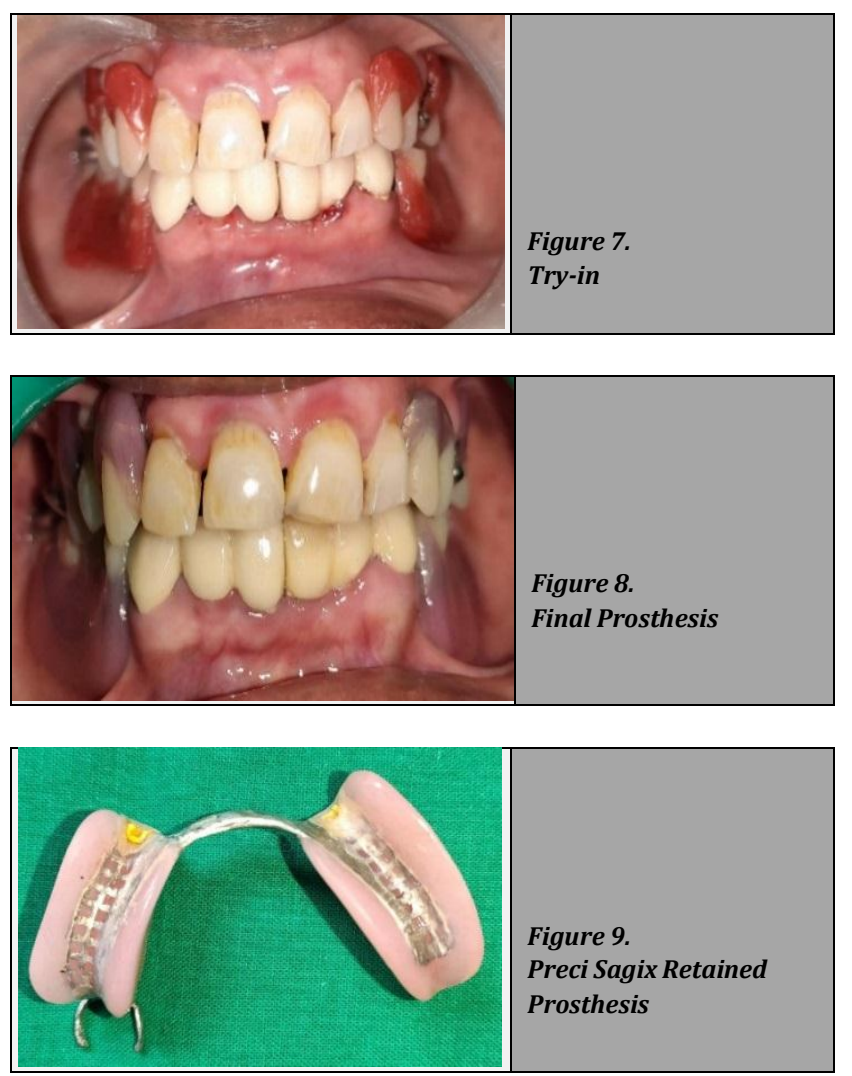

\section{Wax Up Try-In and Final Insertion of Combined Prosthesis}

Once framework fit was evaluated in the mouth, maxillomandibular relationship was recorded and articulated. After the teeth arrangement, try in was done and then cast partial denture was acrylized (Trevalon HI, Dentsply, India) (Figure 8 \& 9).

Mandibular splinted fixed partial denture along with sagix attachments were cemented with GIC and deflective occlusal contacts were corrected. Passive fit of the RPD was checked and then the female component was picked up from sagix into partial denture using self-cure acrylic resin.

\section{Clinical Significance}

This treatment modality ensures restoration of long span edentulous arch with excellent aesthetics and retention as well as improved chewing efficiency with the incorporation of Preci sagix retained cast partial denture.

\section{DISCUSSION}

A growing trend in the application of precision attachment retained prosthesis is seen in dentistry nowadays. Good retention can be accomplished by combining a fixed partial denture and a removable prosthesis by clasps, root caps, intra or extra-coronal attachments. ${ }^{6}$ Whereas by proper selection of attachments and determination of number of guiding surfaces it permits cross arch stabilization and potential force transmission than the clasps. According to Sakshi et al. canines were chosen as abutments because of the strategic position, shape, larger periodontal attachment area and proprioception.7, 8 Semi precision attachment is mainly indicated in long edentulous cases, in increased resorbed bone cases, and in situations that needs cross arch stabilization and to eliminate the unaesthetic appearance along with abrasive act of clasp retainers in conventional dentures. ${ }^{9}$

Preci-sagix attachment which is a sagittal ball attachment with castable plastic male (patrix) and retentive female components (matrix) was the most befitting attachment system that could be incorporated in the treatment regimen of this case. Patrix ball attachments are usually available in varying sizes and have to be positioned as close to the tissue as possible to lessen abutment stress, to avoid food entrapment and to increase interocclusal space. Matrix components are supplied in different colours indicating various means of retention such as red for increased retention, yellow for normal retention and white for reduced retention. Based on the inter-arch space available and for normal retention we have used yellow matrix component for normal retention. The distinctive feature with this attachment is that of the patented snap system as the female component within the housing ensures a snug fit with the male component joined to the splinted crowns. ${ }^{10,4}$ According to Feinberg et al. these attachments are retentive and passive thereby, dispersing the force onto the tooth more apically than occlusally. Thus, the major limitation of the cast partial dentures with distal extension condition is eliminated in this way. ${ }^{8}$

Naveen et al. and Rahul et al. reported Rhein 83 OT Cap attachment system for rehabilitation of bilateral distal 
extension maxillary arch on the distal side of the crowns as extension permitting a good amount of vertical space for best esthetics.11, 12 However in this case, abutments had adequate crown height ratio and a range of $4-5 \mathrm{~mm}$ inter arch space was available which best suited to receive the Preci-sagix attachment. In order to reduce the stress on distal abutment lower anteriors were given splinted crowns for enhancing the success of cast partial denture as proposed by Charkawi et al. ${ }^{12,13}$

Resilient plastic cap of attachment gets abraded eventually and needs to be upgraded every 6 months to ensure its retentive function and to enhance patient's comfort and satisfaction. ${ }^{3}$

\section{CONCLUSIONS}

A well-planned treatment helps in preserving the remaining dentition and a significant increase in retention, stability and function of prosthesis is gained using a semi precision attachment system. Preci-sagix attachment was decided for the current case as an ideal treatment option for distal extension case because of its cost, its retentive function and its uncomplicated laboratory and clinical steps.

Financial or other competing interests: None.

Disclosure forms provided by the authors are available with the full text of this article at jemds.com.

\section{REFERENCES}

[1] Carr A, Brown D. McCracken's removable partial prosthodontics-e-book. $12^{\text {th }}$ edn. Elsevier Health Sciences 2010.

[2] Makkar S, Chhabra A, Khare A. Attachment retained removable partial denture: a clinical report. International Journal of Clinical Dental Science 2011; 2(2).
[3] Prasad DA, Swaminathan AA, Prasad DA. A simplified approach to semi-precision attachment. Journal of Health and Allied Sciences Nitte University 2016; 6(03):51-7.

[4] https://1xm2t81hnle3z46403lln5lk-Wpengine.NetdnaSsl.Com/Wp-Content/Uploads/Bsk-PdfManager/2019/07/Preci-Sagix-Instructions.Pdf

[5] Anne G, Badisa M. Full mouth rehabilitation using fixed partial denture with attachments and conventional lower denture-a case report. International Dental Journal of Students Research 2017; 5(1):25-8.

[6] Uludag B, Polat S, Sahin V, et al. A technique for fabrication of an extracoronal attachment-retained removable partial denture to fit an existing fixed partial denture. J Prosthodont 2012; 21(2):138-40.

[7] Zitzmann NU, Rohnerb U, Weiger R, et al. When to choose which retention element to use for removable dental prostheses. Int J Prosthodont 2009; 22(2):161-7.

[8] Gupta S, Rani S, Sikri A, et al. Attachment retained cast partial denture: conventional and contemporary treatment perspectives. International Journal of Oral Care and Research 2016; 4(4):312-6.

[9] Chander GN. Palliative care with attachment hybrid removable prosthesis. J Clin Diagn Res 2017; 11(1):ZD456.

[10] Marya P, Handa M. Bilateral semi precision removable partial denture using Ceka Preci-Sagix attachment system. Indian Journal of Dental Advancements 2016; 8(4):267-71.

[11] Gupta N, Bhasin A, Gupta P, et al. Combined prosthesis with extracoronal castable precision attachments. Case Rep Den 2013; 2013:282617.

[12] Patil R, Shetty O. Prosthetic rehabilitation using extra coronal attachments. International Journal of Dentistry Research 2019; 4(1):5-8.

[13] El Charkawi HG, El Wakad MT. Effect of splinting on load distribution of extracoronal attachment with distal extension prosthesis in vitro. J Prosthet Dent 1996; 76(3):315-20. 